\title{
Certainty and Explanation in Descartes' Philosophy of Science
}

\author{
Finnur Dellsén \\ Penultimate draft - forthcoming in $H O P O S$
}

\begin{abstract}
This paper presents a new approach to resolving an apparent tension in Descartes' discussion of scientific theories and explanations in the Principles of Philosophy. On the one hand, Descartes repeatedly claims that any theories presented in science must be certain and indubitable. On the other hand, Descartes himself presents an astonishing number of speculative explanations of various scientific phenomena. In response to this tension, commentators have suggested that Descartes changed his mind about scientific theories having to be certain and indubitable, that he lacked the conceptual resources to describe the appropriate epistemic attitude towards speculative theories, or that the presence of geometrical principles in these explanations guarantee their certainty. I argue that none of these responses is satisfactory and suggest a different resolution to the tension by examining Descartes' notion of explanation. On Descartes' view, providing an adequate explanation does not require being certain of the theories that constitute the explanans. Relatedly, the purpose of Cartesian explanations is not to discover the truth about the various underlying mechanisms that such explanations appeal to, but to support his general philosophical thesis that all natural phenomena can be explained by appealing to the extension of matter.
\end{abstract}




\section{Introduction}

In the Principles of Philosophy, Descartes purports to have given scientific explanations of an astonishing number and great variety of observed natural phenomena, often in terms of underlying unobservable mechanisms. These putative explanations are often quite speculative, as Descartes himself seems to acknowledge in the text. However, Descartes also repeatedly claims that any theories presented in science must be certain and indubitable. Thus there is a tension in Descartes' writings between a requirement of certainty for scientific theories and his own speculative explanatory endeavors in the Principles. I argue against three influential attempts to resolve this tension - due respectively to Daniel Garber (1978, 2001), Desmond Clarke (1982, 1992), and Helen Hattab (2009) - and go on to suggest a different resolution to the tension by examining Descartes' notion of explanation. On Descartes' view, providing an adequate explanation does not require being certain of the theories that constitute the explanans. Relatedly, the purpose of Cartesian explanations is not to discover the truth about the underlying mechanisms that such explanations appeal to, but to support his general philosophical thesis that the extension of matter is the only principle required to account for observed natural phenomena.

I will proceed as follows. In section 2, I set the stage by going over the relevant fundamentals of Descartes' general epistemology of science. Then, in section 3, I discuss the aforementioned tension in Descartes' writings, arising roughly from Descartes' requirement of certainty for scientific theories, on the one hand, and his willingness to provide quite speculative putative explanations of natural phenomena, on the other hand. In section 4, I discuss Garber's, Clarke's, and Hattab's attempts to resolve this tension, 
and argue that none of them is satisfactory. In section 5, I analyze Descartes' concept of explanation, showing how it differs substantially from most contemporary conceptions of scientific explanation. In section 6 , I show how the tension from section 3 disappears given this understanding of what is involved in a Cartesian explanation. Finally, in section 7, I discuss some additional advantages of my interpretation. Section 8 is the conclusion.

\section{Descartes' Epistemology of Science}

Let us first go over the basic structure of scientific reasoning in Descartes' philosophical system. Since Descartes did not distinguish between scientific and non-scientific reasoning, we can draw on Descartes' more general account of epistemic reasoning wherever we can find it to make sense of his conception of scientific reasoning. We find this general account displayed most clearly in Descartes' unpublished, but influential, Rules for the Direction of the Mind. ${ }^{1}$ In the Rules, Descartes' view is that all genuine or scientific knowledge (scientia) is grounded in certain and indubitable 'simple natures'. Our knowledge of these simple natures comes from what Descartes calls 'intuition', a direct apprehension of the truth that Descartes describes as "the conception of a clear and attentive mind, which is so easy and distinct that there can be no room for doubt about what we are understanding" (Cottingham et al. 1985a, 14). According to the view Descartes proposes in the Rules, all other knowledge can be inferred from these indubitable intuitions by what Descartes calls 'deduction'.

1 All references to Descartes' writings will be to the two volumes edited and translated by Cottingham, Stoothoff and Murdoch (Cottingham et al. 1985a, 1985b). 
It's important to be clear that Descartes' notion of deduction differs substantially from the purely formal notion of deduction that we find in contemporary logic. Roughly, a Cartesian deduction is a psychological process in which one first intuits the indubitable and self-evident truth of the premises and moves mentally from there to intuit the truth of the conclusion. As we shall see, Descartes similarly believes that it is possible to deduce various scientific theories by moving from intuitions of more basic truths, even though the theories in question are clearly not logically entailed by them. Indeed, Descartes explicitly contrasts his own conception of deduction with the type of purely formal logic with which he was familiar, viz. syllogistic logic, complaining that since the conclusions of syllogistic arguments do not have any content beyond what is already present in the premises, we cannot use them to learn anything new (Cottingham et al. 1985a, 37).2

Now, although all genuine knowledge is ultimately grounded in basic intuitions in virtue of being deducible from them in the above sense, we should not be so rash as to conclude that on Descartes' view the scientific method should always follows this simple route. Descartes does discuss a kind of method - synthesis - which recommends that one start with basic intuitions and deduce from them more specific phenomena. In the Second Replies (to the Meditations on First Philosophy), Descartes displays a summary of his arguments in the Meditations in which he explicitly follows the synthetic method. However, Descartes also clearly indicates that he prefers a different method of showing that some

\footnotetext{
2 A lot more can be said about the nature of Cartesian deductions, and how they differ from both a contemporary conception of deduction and the syllogistic deduction used by Descartes' predecessors. For relevant discussions, see Wong (1982), Gaukroger (1989), Normore (1993), Owen (1999, ch. 2), Nelson (2015), and Rogers and Nelson (2015).
} 
specific phenomena can be deduced from basic intuitions, viz. analysis. ${ }^{3}$ While there is a significant debate in the secondary literature about the nature of this method and how it relates to Descartes synthetic method, it's clear that analysis starts with the various phenomena that one aims to show to be deducible from basic intuitions. One then works backwards, at each step figuring out what would have to be true for the step in question to hold, until - hopefully - one arrives at the basic intuitions. If successful, one is then immediately in a position to deduce the phenomena from the basic intuitions just as if one had done a synthesis instead of an analysis. ${ }^{4}$

Descartes famously presented three overarching principles from which he claimed that all other knowledge could be deduced. Most relevant to scientific knowledge is Descartes' principle of extension, according to which there exist bodies that are by their very nature extended in space: "extension in length, breadth and depth constitutes the nature of corporeal substance" (Cottingham et al. 1985a, 210). In addition, we have the principle of thought, according to which there also exist thinking substances, or souls. Finally, a

3 Indeed, Florka (2001) argues for the stronger view that Descartes rejected synthesis altogether. As Florka correctly notes, Descartes was suspicious of synthesis since he associated it with the syllogistic logic that he famously rejected as useless for discovering genuine knowledge. However, even Florka must acknowledge that deductions discovered by analysis can be presented, as Descartes puts it, "in the synthetic style" (Cottingham et al. 1985b, 113), since such a presentation of the Meditations is in fact partly provided by Descartes in the Second Replies. Thus, while synthesis may be useless as a method for discovering new truths on Decscartes' view, Descartes does not appear to have thought it useless for all purposes.

${ }^{4}$ This is not to say that the purpose or goal of an analysis is to eventually be able use the synthetic method to derive the phenomena. On the contrary, Descartes' comments in the Second Replies along with the fact that the Meditations were not written in the synthetic style, indicate that he considered synthesis to be of quite limited value. (See also the preceeding foonote.) 
different kind of substance altogether - God - exists and is by its very nature infinitely perfect in every way (infinitely good, infinitely powerful, infinitely knowing, etc.). We can call this the principle of God's infinite perfection. On Descartes view, all three 'first principles' are self-evident and thus certain and indubitable, but Descartes' more interesting claim is that all natural phenomena can be deduced from them.

How exactly are natural phenomena supposed to be deduced from these principles? The first step is to use the principles to deduce laws of motion for material bodies. In deducing these laws, Descartes appeals not only to the principle of extension, but also to the principle of God' infinite perfection. For example, Descartes appeals to the God's infinite perfection to support the claim that God is immutable, and would thus create a world in which the total amount of motion remains constant through time. This result about the total amount of motion in the world is used as an assumption in the deduction of the first law of motion, according to which all simple and undivided things never change unless they are acted on by external causes. In an analogous way, Descartes deduces two other laws of motion from his first principles. ${ }^{5}$

Having deduced these laws of motion from first principles, Descartes proceeds systematically, in part III of the Principles, to deduce various mechanical theories from these laws. The idea is to find mechanical theories from which the observed phenomena

\footnotetext{
5 The last of these laws concerns the collision of bodies. Having deduced this law, Descartes goes on to give seven rules for calculating the motions of bodies that collide. These rules don't quite fit into the neat structure of principles, laws, mechanism, and phenomena that Descartes usually seems to be giving us. I'll ignore this complication below, since it is (as far as I can see) orthogonal to the issues I'll be focusing on.
} 
can themselves be deduced, closing the gap between first principles and the phenomena one encounters in nature. How precisely Descartes thinks one should proceed in finding such theories is contentious, and we'll look into that momentarily. But it's at least clear that here Descartes can use both the laws of motion and the observed phenomena as a guide in his scientific theorizing. So Descartes' mechanical theories are constrained both by higher-level laws of motion, and by lower-level observed phenomena. However, it is evident to any attentive reader of Descartes that the laws and the phenomena do not by themselves generally rule out all but one such theory in a given case. This basic fact about Descartes' mechanical theories takes us to an apparent tension in Descartes' writings, to which we now turn.

\section{Certainty and Scientific Theories}

A standard complaint about Descartes is that he had too high standards for what we would now call epistemic justification. Although this complaint often rests on a simplistic and anachronistic reading of Descartes, there is surely some truth in the claim that knowledge, on Descartes' view, requires certainty or indubitability. The second rule in the Rules states that "[w]e should attend only to those objects of which our minds seem capable of having certain and indubitable cognition" (Cottingham et al. 1985a, 10). The reasoning behind the rule is very revealing:

All knowledge is certain and evident cognition. Someone who has doubts about many things is no wiser than one who has never given them a thought; indeed, he appears less wise if he has formed a false opinion about any of them. Hence it is better never to study at all than to occupy ourselves with objects which are so difficult that we are 
unable to distinguish what is true from what is false, and are forced to take the doubtful as certain; for in such matters the risk of diminishing our knowledge is greater than our hope of increasing it. So, in accordance with this Rule, we reject all such merely probable cognition and resolve to believe only what is perfectly known and incapable of being doubted (Cottingham et al. 1985a, 10).

In the Discourse on the Method, Descartes' very first rule for attaining knowledge was

[...] never to accept anything as true if I did not have evident knowledge of its truth: that is, carefully to avoid precipitate conclusions and preconceptions, and to include nothing more in my judgements than what presented itself to my mind so clearly and so distinctly that I had no occasion to doubt it (Cottingham et al. 1985a, 120).

And, in the Principles, Descartes explains that the reason his opponents in the Schools have been "unable to arrive at knowledge of true principles" is that

$[\ldots]$ they have all put forward as principles things of which they did not possess perfect knowledge. For example, there is not one of them, so far as I know, who has not supposed there to be weight in terrestrial bodies. Yet although experience shows us very clearly that the bodies we call 'heavy' descend towards the centre of the earth, we do not for all that have any knowledge of the nature of what is called 'gravity', that is to say, the cause or principle which makes bodies descend in this way, and we must derive such knowledge from some other source (Cottingham et al. 1985a, 182-3).

Descartes concludes that "none of the conclusions deduced from a principle which is not evident can themselves be evident, even though they may be deduced from the principle in an evident manner" (Cottingham et al. 1985a, 183). In fact, the situation is even worse, as Descartes brings out with an analogy: 
$[\ldots]$ so long as we turn our back on the place we wish to get to, then the longer and faster we walk the further we get from our destination, so that even if we are subsequently set on the right road we cannot reach our goal as quickly as we would have done had we never walked in the wrong direction. The same thing happens if we have bad principles. The more we develop them and the more carefully we work at deducing various consequences from them in our belief that we are philosophizing well, the further we move from knowledge of the truth and from wisdom (Cottingham et al. 1985a, 183).

Having false beliefs can be quite destructive, on Descartes' view - worse than having no beliefs at all.

It's worth emphasizing that Descartes' requirement of certainty, as I will call it, is no mere accidental feature of his philosophy that can be detached and discussed in isolation from his broader philosophical project. As Descartes explains in the passages above, any uncertainty at a higher level will generate even more uncertainty at a lower level. For example, if Descartes were uncertain about his laws of motion, then the scientific theories derived from them would be at least equally - and probably more - uncertain. So, somehow, Descartes clearly thinks that we must have absolute certainty, or perfect knowledge, of anything we use in our scientific theorizing. If we don't, the whole Cartesian project of deducing phenomena from first principles seems doomed.

The requirement for certainty conflicts rather severely with Descartes' practice of giving various detailed scientific explanations in the Principles. To take a well-known example, Descartes explained the behavior of magnetic bodies by positing unobservably small screw-like particles and giving a very detailed story about how these tiny screws pushed ferromagnetic objects towards the poles of magnets. Furthermore, Descartes' 
many explanations cover a great deal of quite varied natural phenomena. The discussion of these explanations stretches over more than 300 articles, wherein Descartes explains everything from why bodies fall towards the earth to why glass is transparent. Near the end of the principles, Descartes even announces that "there is nothing in the whole of nature $[\ldots]$ which is incapable of being explained on the basis of these selfsame principles" (Cottingham et al. 1985a, 279).

Many of the detailed theories Descartes proposes to explain various natural phenomena are quite ingenious. In that respect, Descartes' scientific project looks quite familiar to a contemporary reader. On the other hand, a contemporary reader is bound to be at least somewhat disappointed when she looks for Descartes' reasons for proposing these theories rather than alternative theories. Of course, the theories Descartes proposes are constrained somewhat by the fact that they are part of a deduction from first principles to phenomena. That is, an adequate explanation must invoke theories that are consistent both with first principles and laws of motion - from which they are deduced and with observable phenomena - which are derived from them. But although this certainly constrains the theories available for use in scientific explanations, it does not at all single out the theories Descartes ends up proposing, except perhaps in exceptional cases. Why, for example, does Descartes think that the tiny particles that emerge from magnets are screw-shaped rather than, say, shaped like spikes?

Descartes seems to have recognized this mismatch between evidence and theory in the Principles. Descartes' explanations of heavenly phenomena are prefaced by Descartes telling the reader that he wishes to "put forward everything that I am about to write simply as a hypothesis", adding in the French edition that such a hypothesis "is 
perhaps far from the truth" (Cottingham et al. 1985a, 255). The same goes for Descartes' theory about the motion or otherwise of the earth: "I wish this to be considered simply as a hypothesis [addition in the French edition: "or supposition that may be false"] and not as the real truth" (Cottingham et al. 1985a, 251). But the clearest indication that Descartes had reservations about the epistemic status of his scientific theories is perhaps to be found in one of the last articles of the Principles:

$[\ldots]$ although this method may enable us to understand how all the things in nature could have arisen, it should not therefore be inferred that they were in fact made in this way. Just as the same craftsman could make two clocks which tell the time equally well and look completely alike from the outside but have completely different assemblies of wheels inside, so the supreme craftsman of the real world could have produced all that we see in several different ways. I am very happy to admit this $[\ldots]$ (Cottingham et al. 1985a, 289).

Descartes is very happy to admit that his scientific theories may very well be mistaken.

Somehow, being wrong about the mechanical theories deduced at the penultimate step of a Cartesian deduction doesn't bother Descartes at all. Yet this is clearly in tension with his requirement of certainty, which is unambiguously expressed in the Rules, the Discourse and in the Principles themselves. Note that the requirement of certainty is present even in the preface to the French edition, which was written after the Latin text had already been published and so would have been a perfect opportunity for Descartes to relax or abandon the requirement. Instead, as we have seen, Descartes does the opposite. There is clearly a tension here: How can Descartes uphold his requirement of certainty and yet give so blatantly speculative explanations in the Principles - explanations that he admits may be "far from the truth"? Is Descartes violating his own methodological and 
epistemological strictures when he gives scientific explanations for observed natural phenomena?

\section{Resolutions in the Secondary Literature}

This tension has not gone unnoticed in the secondary literature. In this section, I discuss three different attempts to resolve the tension in the secondary literature, due respectively to Daniel Garber (1978, 2001), Desmond Clarke (1982, 1992), and Helen Hattab (2009). Although I will argue that none of these commentators have resolved the tension in an entirely satisfactory manner, it seems to me that much of what they point out is not only compatible but also complementary to what I will end up arguing is the correct resolution to the tension. In this section, however, I want to highlight the points at which I think their resolutions fall short.

Garber (1978, 2001), impressed by the apparently conflicting remarks Descartes makes concerning certainty and his own theorizing, suggests that Descartes simply changed his mind about whether certainty was possible concerning the unobservable causes of observed phenomena. For whatever reason, Descartes came to realize that a form of hypothetical reasoning (what we might now call hypothetico-deductive reasoning), which is less secure than Cartesian deduction, was necessary in natural science. This change, on Garber's view, took place sometime after writing the Rules, the Discourse, and the Essays, but before writing the Principles, where most of Descartes' scientific theorizing takes place. However, Garber makes no serious attempt at explaining why Descartes came to think that his method of deduction from first principles was 
inadequate and why this form of hypothetical reasoning would therefore be indispensible. ${ }^{6}$

Garber's suggestion faces at least three serious problems. First, Garber gives us no independent evidence for the thesis that Descartes changed his mind so dramatically between writing the Principles and his earlier work. So the presumption should surely be that Descartes saw the philosophical and scientific project in the Principles as a continuation of his earlier philosophical projects. Second, as we have seen, Descartes continues to claim that scientific theorizing must be certain even in the Principles. Thus, contrary to what Garber seems to be assuming, the relevant tension in Descartes' thought is not merely a tension between what Descartes says in the Principles and what he says in earlier writings. Third, and finally, if there was such a change in Descartes' thought concerning the certainty required of scientific theories, one should expect that change to have come about not between the Essays and the Principles, but before the Essays (and thus before the Discourse). After all, a large part of the Essays contain the very same kind of

${ }^{6}$ Garber does end his discussion of the issue with some speculations as to why Descartes might have changed his mind:

Perhaps he came to appreciate the obscurity of the appeal to intuition, his earlier conception of how corpuscular substructures are to be found, and saw in hypothetical argument the clarity he sought, even if it meant sacrificing certainty. Perhaps in actually working out and defending his views on the inner nature of things, he came to appreciate the sheer complexity of nature, and saw in hypothetical argument a better way of coming to grips with the world. But for whatever reason, Descartes was led to give up his earlier extravagant claims about what we can know and how, in favor of the relatively more modest claims in the Principia (Garber 2001, 129). 
speculative theorizing as do the Principles. In sum, then, there seem to be strong reasons to continue to look for a better way of understanding of Descartes' scientific project. 7

We turn next to Clarke's $(1982,1992)$ interpretation. On Clarke's view, it's a mistake to think that Descartes required certainty of the scientific explanations that he gives in the Principles. Rather, Clarke argues that Descartes' apparent claims of certainty concerning his scientific explanations are due to his lacking a concept of probability between absolute certainty and mere guesswork - a concept that is appropriate to the kind of confirmation that is obtained by hypothetical reasoning. The idea is that because Descartes lacked any concept of this in-between epistemic state, he was sometimes forced to convey that his scientific explanations were not merely guesswork by calling them 'certain', and at other times he needed to convey that they were less certain than, say, his first principles, by denying that these explanations were, again, 'certain'. On Clarke's view, then, the apparent conflict in Descartes' writing is due to a kind of conceptual deficiency that plagued Descartes as well as his contemporaries: "Descartes' efforts to describe the degree of certainty that resulted from his scientific practice are best understood as a doomed attempt to classify the probability produced by the new scientific method in the language of the scholastics" (Clarke 1992, 275).

There are at least two serious problems with Clark's suggestion, however. First, while Descartes obviously lacked anything like the contemporary concept of probability, ${ }^{8}$

7 To be sure, Garber (1978) acknowledges that his suggestion is speculative, noting that " $[\mathrm{t}]$ hough Descartes' goal was certainty, mine is not." Garber presents his interpretation merely as "one line for reinterpreting [Descartes'] scientific enterprise" $(1978,116)$. 
it does not follow that Descartes could not express an intermediate epistemic status between certainty and mere speculation. After all, Descartes would surely have been capable of constructing his own concept of an intermediate kind of epistemic status had he thought it served an important purpose, such as to clarify the epistemic status of his scientific explanations. Indeed (and this is the second problem with Clarke's suggestion) Descartes does sometimes use a concept of a kind of in-between epistemic state: At the end of the Principles, Descartes explicitly considers the possibility that his explanations may only possess 'moral certainty', which can fall short of 'absolute certainty' (Cottingham et al. 1985a, 289-290). So why didn't Descartes just say throughout that his scientific explanations were 'morally certain'? At the very least, this suggests that Descartes was well aware of the possibility of describing scientific theorizing in an epistemically nuanced manner.

A final discussion bearing on the aforementioned tension in Descartes' thought can be found in the work of Helen Hattab (2009). Hattab argues that Descartes' scientific demonstrations, both in his earlier work and also in the Principles, appealed to various geometrical principles about sensed objects. Hattab agrees with Garber and Clarke that Descartes is employing a form of hypothetical reasoning in which we reason from effects to causes by first showing how the effects can be deduced from the causes. However, in contrast to Garber and Clarke, Hattab emphasizes that Descartes' geometrical principles play a crucial role as premises in this hypothetical form of reasoning. On Hattab's view,

8 The very concept of mathematical probability, along with the probability calculus itself, had not yet been developed when Descartes was writing the Principles in and before 1644, but it would develop quite rapidly soon afterwards (see Hacking 2006). 
the occurrence of these geometical principles within such a hypothetical form of reasoning explains why Descartes frequently calls his demonstrations 'mathematical'. Furthermore (and more relevantly for our purposes), Hattab claims that the presence of geometrical principles in Descartes' demonstrations, in the Principles and elsewhere, "guarantees the certainty of the conclusion that is demonstrated" (Hattab 2009, 131). Contra Garber and Clarke, Hattab thus concludes that Descartes took himself to have upheld his requirement of certainty in the Principles after all (Hattab 2009, 132).

While Hattab's account of the role of geometrical principles in Cartesian demonstrations is illuminating in many respects, it is deeply problematic as a resolution of the tension between Descartes' requirement of certainty and his speculative explanations in the Principles. One problem is that what Hattab refers to as the "conclusions" of Descartes' demonstrations are not the mechanical theories that serve as the explanantia in Descartes's explanations but the observed natural phenomena that serve as the explananda. ${ }^{9}$ As Garber and Clarke both emphasize, however, the tension in Descartes' thought between his speculative explanantions and his requirement of certainty do not arise at the level of the observed explananda but at the level of the speculative explanantia. So even if Hattab were right that the presence of geometrical principles in Cartesian demonstrations guarantees the certainty of their conclusions (i.e. the

\footnotetext{
${ }^{9}$ Here I am following standard philosophical usage in calling the things that do the explaining in an explanation explanans (plural: explanantia) and the things that are explained in an explanation explanandum (plural: explananda). Note that on this terminology an explanation is neither identical to its explanandum nor its explanans.
} 
explananda), this would not resolve the tension since it is not the certainty of these conclusions that is at issue. ${ }^{10}$

Another problem with Hattab's account is that there is no reason why Descartes would think that the presence of geometrical principles within his demonstrations would by itself bestow any kind of certainty on its conclusions. Of course, if Descartes' conclusions could be derived from geometrical principles alone, then Descartes could reasonably claim that the conclusions have as much certainty as the geometrical principles themselves. However, as Hattab (2009, 130-131) herself notes, these geometrical principles only function as the "middle terms" of demonstrations that begin by assuming the very mechanical theories whose epistemic status is at issue. Since these mechanical theories obviously cannot be assumed to be certain at this point (i.e. prior to making the hypothetical arguments for them), such a "demonstration" would obviously not guarantee the certainty of the conclusion. If Descartes thought otherwise he would have been guilty of the elementary epistemological mistake of attributing certainty to a conclusion of an argument in virtue of the fact that one of its premises is certain.

In sum, Hattab's otherwise illuminating account of the role of geometrical principles in Cartesian demonstrations is of no help in resolving the aforementioned tension in Descartes' thought. Clarke's proposal that Descartes lacked a concept of an in-

10 To be sure, if Descartes employed a form of hypothetical reasoning, there is a sense in which it is the certainty of conclusions that is at issue. That is, what is at issue is the certainty of the hypotheses inferred in hypothetical reasoning - and we may want to refer to these hypotheses as the "conclusions" of hypothetical inferences. It is clear, however, that this is not how Hattab is using the term. Rather, Hattab uses 'conclusion' in this context to refer to the propositions that are deduced from the hypotheses. 
between epistemic state is both implausible in its own right and in conflict with Descartes' proclamations in the final passages of the Principles. Finally, Garber's suggestion that Descartes abandoned the requirement of certainty before writing the Principles conflicts with textual evidence and is implausible in light of the timeline of Descartes' work. I therefore suggest that we look for another resolution to the tension between Descartes' requirement of certainty for scientific theories and his speculative explanations in the Principles.

\section{Cartesian Explanations}

In this section and the next, I argue that the key to resolving the tension described in section 3 is to understand what an explanation is in Descartes' philosophical system. Descartes does not tell us explicitly how he thinks of explanations, e.g. by giving a definition or general characterization, but we can piece together a good enough understanding from various remarks in the Principles and elsewhere. It turns out, I will argue, that Descartes' conception of scientific explanations differs significantly from standard contemporary conceptions in at least two important ways.

The first thing to note is that Cartesian explanations are, in a sense to be explicated, the converse of Cartesian deductions. This is evident from a number of passages in the Principles, for example:

$[\ldots]$ in order to come to know the true nature of this visible world, it is not enough to find causes which provide an explanation of what we see far off in the heavens; the selfsame causes must also allow everything which we see right here on earth to be deduced from them. There is, however, no need for us to consider all these terrestrial 
phenomena in order to determine the causes of more general things. But we shall know that we have determined such causes correctly afterwards, when we notice that they serve to explain not only the effects which we were originally looking at, but all these other phenomena, which we were not thinking of beforehand (Cottingham et al. 1985a, 255).

As this reveals, Descartes uses 'explanation' as a different way of saying that something can be deduced from something else. So, on Descartes' view, $A$ explains $B$ if and only if $B$ can be deduced from $A$. However, we must also remember what is involved in a Cartesian deduction. For Descartes, one cannot simply take a proposition at random and deduce something from it. Unless such a proposition represents an idea that is itself either intuited directly or deducible from an intuited idea, it will be confused and thus not eligible to serve as the premise of a further deduction. This is why, as we saw in section 3, deductions must start from first principles - self-evident truths - or start from something else that can itself be deduced from first principles. This is not to say that nothing but first principles can be used or appealed to in a Cartesian deduction - indeed, it has been argued convincingly that Descartes frequently appeals to various other facts and assumptions in his deductions, at least in his later works. ${ }^{11}$ But it does mean that a Cartesian deduction must be at least partly grounded in first principles in the sense that the first principles must figure in the deduction when it is spelled out in full detail.

\footnotetext{
${ }^{11}$ In particular, there is clearly an important sence in which experience enters into such deductions. For example, in order to deduce (in a Cartesian sense) that magnets emit screw-like particles, Descartes needs to make certain empirical observations about the actual behaviour of magnetic objects. That being said, there is little agreement in the secondary literature on exactly what role experience plays in Cartesian deductions (see, e.g, Garber 1993 and references therein).
} 
This tells us something important about Descartes' conception of explanation. Since $A$ explains $B$ if and only if $B$ can be deduced from $A$, and since $B$ can be deduced from $A$ only if $A$ is itself deducible from first principles, it follows that $A$ explains $B$ only if $A$ can itself be explained by appealing to first principles. This is why Descartes finds it appropriate, in The World, to reject explanations of the properties of material bodies that appeal to scholastic forms such as heat, cold, moisture, and dryness on the grounds that "these qualities themselves seem to me to need explanation" (Cottingham et al. 1985a, 89). This argument would be a complete non sequitur unless Descartes thought that explanations must at least partly bottom out in something that does not itself need to be explained, viz. the self-explanatory first principles. Note how this differs from standard contemporary conceptions of explanations: We do not now ordinarily think that explaining something requires that both it, and the thing that explains it, be at least partly explainable by more explanatorily basic principles. Throwing the baseball towards the window explains, we think, why the window shattered, independently of whether the throwing of the baseball can itself be explained by some more basic principles.

Descartes' conception of explanations as requiring a kind of explanatory grounding in first principles may seem quite puzzling in the eyes of a contemporary reader. On Descartes' conception of explanation, whenever $A$ explains $B$ it follows conceptually that the first principles (from which $A$, and thus $B$, can be deduced) can also be used to explain $B$. Thus, to show that anything explains a given phenomenon is to show that the first principles can be used to do so as well. This is important, as I'll argue in more detail below, because it means that an argument that Descartes makes for some $A$ 
explaining some $B$ may ultimately be an argument for the conclusion that the first principles can be used to explain $B$. (We will return to this in section 6 below.)

The next thing to note is what this requirement of explanations being grounded in first principles implies about explanations of natural phenomena. Since all natural phenomena, in some way or another, concern the behaviors of material bodies, it is clear that in a Cartesian deduction from first principles one must appeal to the first principle that Descartes thinks governs such bodies, viz. the principle of extension. So, in this sense, all scientific explanations must ultimately be grounded in the principle of extension. This requirement of deducibility of explanantia from the principle of extension tells us something extremely important about Descartes' view of scientific explanations: all scientific explanations must be mechanical explanations. This is because only mechanical explanations could be grounded in the principle of extension in the appropriate way. A non-mechanical explanation - e.g. the explanation of magnetism in terms of brute magnetic powers - is not deducible from the principle of extension, because what distinguishes a magnet from other things, on a non-mechanical explanation, is not spelled out in terms of the different extensions of such bodies, or any upshot thereof (such as their motions or positions). In sum, all explanations of natural phenomena must necessarily be mechanical, for Descartes, since any non-mechanical explanation fails to be grounded in the principle of extension.

Another feature of Cartesian explanations that might surprise a contemporary reader is that, for Descartes, theories can explain even if they are not true. As a corollary,theories can serve as part of the explanans of an adequate act of Cartesian explanation even if they are not taken to be true by the explainer. This is apparent from a 
number of illuminating passages in the Principles. In the most famous such passage, Descartes explicitly claims that theories that are known to be false can sometimes provide better explanations than theories that are known to be true:

$[\ldots]$ in order to provide a better explanation for the things found in nature, I shall take my investigation of their causes right back to a time before the period when I believe that the causes actually came into existence. [...] if we want to understand the nature of plants or of men, it is much better to consider how they can gradually grow from seeds than to consider how they were created by God at the very beginning of the world. Thus we may be able to think up certain very simple and easily known principles which can serve, as it were, as the seeds from which we can demonstrate that the stars, the earth and indeed everything we observe in this visible world could have sprung. For although we know for sure that they never did arise in this way, we shall be able to provide a much better explanation of their nature by this method than if we merely described them as they now are [French edition adds: "or as we believe them to have been created] (Cottingham et al. 1985a, 256). ${ }^{12}$

There are, of course, obvious religious motivations for Descartes to include this submission to church doctrine in the Principles. However, that doesn't explain why Descartes thought that this tension between his explanations and church doctrine could be resolved in the manner suggested in the passage. If Descartes had taken explanations to require true explanantia, then Descartes' comments in the passage do nothing at all to resolve the conflict. Thus, if Descartes was indeed worried about contradicting church doctrine, one should expect Descartes to have addressed this conflict in much more detail

\footnotetext{
${ }^{12}$ See also very similar comments in the Discourse, part V (Cottingham et al. 1985a, 133-134).
} 
so as to at least provide the beginnings of a genuine resolution. By contrast, if Descartes had a more liberal conception of explanation on which false hypotheses could serve as explanantia in scientific explanations, Descartes' brief treatment of the tension is entirely appropriate: the issue does not need to be discussed further because on this conception there is no conflict at all between appealing to a hypothesis in an explanation and simultaneously recognizing that it is not true.

Besides, this is not the only passage in which Descartes commits to it being possible for false hypotheses to figure in genuine explanations. For example, article 15 in part III is entitled "The observed motions of the planets may be explained by various hypotheses." In the article, Descartes tells us that "astronomers have produced three different hypotheses, i.e. suppositions, which are regarded not as being true, but merely as being suitable for explaining the appearances." (Cottingham et al. 1985a, 250) Since at most one of these three hypotheses could be true, this implies that on Descartes' conception of explanation, the explanantia of adequate explanations need not be true. Since there are no religious motivations in play here, there is no reason not to take this assertion and its implications at face value. ${ }^{13}$

Now, one consequence of this feature of Cartesian explanations is that perfectly good Cartesian deductions can contain steps that are not regarded as true. To see how this follows, just recall that explanations are simply the converse of deductions grounded in first principles. So if explanations can contain explanantia that are not regarded as true, the steps in a Cartesian deduction can also not be regarded as true. This fits with

${ }^{13}$ See also Principles, part III, article 44 (Cottingham et al. 1985a, 255). 
various remarks that Descartes makes about deductions, for example the following passage in the Discourse:

I venture to say that I have never noticed anything in them [Descartes' senses] which I could not explain quite easily by the principles I had discovered. But I must also admit that the power of nature is so ample and so vast, and these principles so simple and so general, that I notice hardly any particular effect of which I do not know at once that it can be deduced from the principles in many different ways; and my greatest difficulty is usually to discover in which of these ways it depends on them (Cottingham et al. 1985a, 144).

Clearly, since at most one of these "many different ways" of deducing the phenomena goes through a theory that is regarded as true, a deduction can go through steps that are not regarded as true and still count as a Cartesian deduction.

We have seen that explanations need not be regarded as true, and certainly need not be known to be true. Does this mean that any explanation will do, as long as it is mechanical? No. It is clear both from what Descartes says about explanations, and from the particular explanations that he gives, that an adequate explanation must also be the clearest and most distinct of the available explanations. And of course, the mechanical explanations must also be consistent with the observations it explains and be deducible from the laws of motion. However, although this puts constraints on adequate Cartesian explanations, it does not mean that the explanantia in such explanations need to be regarded as true, and it certainly does not mean that they need to be known to be true.

Our conclusions so far about the role of truth in Cartesian explanations will no doubt sound quite strange to a contemporary reader who is used to thinking of genuine 
explanations as requiring true explanantia. ${ }^{14}$ In what sense, such a reader will ask, could an explanation be correct or adequate if the theories to which it appeals are not true or at least believed to be true? The answer becomes clearer if we take care to distinguish a contemporary distinction first drawn explicitly by William Dray (1957) between whyactually explanations and how-possibly explanations. The former is what is standardly referred to with the unqualified term "explanation" in contemporary philosophical parlance. By contrast, the latter - how-possibly explanations - are invariably discussed separately and carefully contrasted with regular (i.e. why-actually) explanations. ${ }^{15}$ In brief, a how-possibly explanation shows how something (the explanandum) could possibly be the case given certain constraints, and thus answers the question "How could this (possibly) be the case?" rather than the more standard explanation-seeking why-question "Why is this (actually) the case?"16

14 The requirement that explanantia be true was explicitly made in Hempel and Oppenheim's (1948) seminal article on scientific explanations, which set the stage for the ensuing debate about scientific explanations in the latter half of the $20^{\text {th }}$ century. This requirement is rarely questioned, although see van Fraassen (1980, 97-101) for a notable exception.

15 See, for example, Salmon (1992, 9-10).

16 Another way of characterizing the distinction between why-actually explanations and howpossibly explanations is in terms of what sort of presumption is being rebutted in the explanation. This is how Dray distinguishes the two kinds of explanations at one point in his original discussion:

In explaining why something happened, if a presumption enters at all, we rebut a presumption that it need not have happened, by showing that, in the light of certain considerations (perhaps laws as well as facts), it had to happen. But in explaining how something could have happened, we rebut the presumption that it could not have happened, by showing that, in the light of certain further facts, 
Note that perfectly adequate how-possibly explanations can appeal to hypotheses that are not regarded as true. For example, I might explain how it is possible that my colleague Smith could afford a Ferrari by suggesting that perhaps he won the lottery. This would be a correct how-possibly explanation since it lays out a possibility on which Smith would afford the Ferrari, even though I may find it highly unlikely that this possibility has been actualized. ${ }^{17}$ Note also that although why-actually explanations and how-possibly explanations are distinct kinds of explanation, there is an intimate logical relationship between them in that a how-possibly explanation illustrates by example that a corresponding why-actually explanation could be correct. For example, having explained how it is possible for Smith to have bought a Ferrari by suggesting that perhaps he won the lottery (a how-possibly explanation), I have also proved that it could be that Smith was actually able to buy a Ferrari because he won the lottery (which would be a why-actually explanation).

Now, since the distinction between why-actually and how-possibly explanations was not available to Descartes, it is not unreasonable to assume that at least some of what Descartes says about explanation applies to the wider category of explanations which includes both standard why-actually explanations and their frequently overlooked sibling, how-possibly explanations. Indeed, some of Descartes' comments about explanations

there is after all no good reason for supposing that it could not have happened (Dray 1957, 161).

${ }^{17}$ Indeed, I might even be certain that my suggestion is correct qua how-possibly explanation, i.e. that this is a possible way in which Smith could have financed the Ferrari, even while consistenly finding it highly unlikely that Smith won the lottery. 
make little sense on the narrow conception of explanations that includes only whyactually explanations to the exclusion of how-possibly explanations. For example, we have seen that at the end of the Principles Descartes claims that although his method "may enable us to understand how all the things in nature could have arisen, it should not therefore be inferred that they were in fact made in this way" (Cottingham et al. 1985a, 289). Later in the same article, Descartes adds that the same is true of Aristotle's explanations in the Meteorologica (as if to show that he is not operating with an ideosyncratic conception of scientific explanations):

[W] hen dealing with things not manifest to the senses, [Aristotle] reckons he has provided adequate reasons and demonstrations if he can simply show that such things are capable of occurring in accordance with his explanations (Cottingham et al. 1985a, 289).

Descartes' talk of using his explanations to understand how things "could have arisen" and show how they "are capable of occurring" strongly suggests that Descartes was at least sometimes referring to what we would now call how-possibly explanations.

I do not mean to suggest that Descartes consistently used the term 'explanation' as specifically referring to how-possibly explanations to the exclusion of why-actually explanations. Since Descartes cannot be expected to have drawn this distinction at all, Descartes is most likely to have been struggling to express his views in the Principles using a single concept to describe two importantly different kinds of things. ${ }^{18}$ So while Descartes may sometimes have been using 'explanation' to refer to why-actually explanations, we

18 Descartes' situation in this regard would be similar to that of Newtonian physicists using a single concept of mass before the distinction between rest mass and relativistic mass was introduced in special relativity. 
have seen evidence that Descartes is at least sometimes using the same term to refer to how-possibly explanations as well. The important point here is just that we can make sense of Descartes' contention that explanations need not appeal to true hypotheses by the independently plausible and textually supported suggestion that Descartes' concept of explanation is not as precise as the contemporary conception on which all explanations, unless otherwise specified, are assumed to be why-actually explanations.

Concluding this section, we have seen that an explanation requires both more and less on a Cartesian conception than it does on most contemporary conceptions - less because the theories used in an explanation need not be regarded as true in every case, and more because an explanation requires a deductive link with first principles, which in turn means that all scientific explanations must be mechanical. Together, I think, these two features of Cartesian explanations resolve the apparent tension described in section 3.

\section{Resolving the Tension}

Recall that the tension described in section 3 was between Descartes' requirement of certainty for scientific theories, on the one hand, and Descartes' practice of giving what he himself recognized as speculative mechanical explanations for various natural phenomena. As we saw in section 4, the interpretations proposed by Garber, Clarke, and Hattab do not resolve this tension in an adequate manner. In this section, equipped with the understanding of Cartesian explanations that I have just given, I will attempt to do better in this regard. Specifically, I shall argue that Descartes' practice of giving speculative mechanical explanations is perfectly consistent with his requirement of certainty for scientific theories, given the right account of Cartesian explanations. 
As we have seen, an adequate explanation of something, on the Cartesian conception, does not necessarily require the explanans to be true. So, a fortiori, to be certain that something is an adequate explanation does not necessarily require being certain that the explanans is true. ${ }^{19}$ What is required is that the explanation be the clearest and most distinct mechanical explanation that fits with observed natural phenomena, the relevant laws of motion, and Descartes' first principles. So long as the mechanical theory Descartes can come up with meets these quite weak requirements, the theory may serve as the explanans in an explanation of some natural phenomena. Because this is all that's required of some explanations, Descartes can be certain of these explanations even though he is uncertain about the mechanical theories that serve as the explanantia in such explanations.

If this seems puzzling, recall how why-actually explanations differ from howpossibly explanations in that the latter can be regarded as correct or adequate even if one does not believe that the hypotheses appealed to in them are true. By the same token, one can be certain that a how-possibly explanation is correct or adequate (qua how-possibly explanation) while consistently being uncertain about the hypotheses that serve as the explanantia. For example, I might be certain that Smith's winning the lottery is is a possible way in which Smith could have financed his Ferrari even though I find it highly unlikely that Smith in fact bought a winning ticket. Similarly, Descartes can be certain that magnetism could consist in the movement of tiny screw-like particles that push

19 This follows from the more general principle that if some proposition $\mathrm{P}_{1}$ is not a necessary condition for another proposition $\mathrm{P}_{2}$, then being certain that $\mathrm{P}_{1}$ is true is not a necessary condition for being certain that $\mathrm{P}_{2}$ is true. 
ferromagnetic objects towards magnetic poles while simultaneously recognizing that a rival theory is quite possibly true. In that case, Descartes would be certain about a howpossibly explanation while being uncertain about the corresponding why-actually explanation.

You might think that this makes Cartesian explanations too easy to get. It's certainly true that many scientific explanations are, in an important way, much easier to achieve on the Cartesian picture than on most contemporary conceptions. But this is something Descartes acknowledges explicitly. Recall Descartes' seemingly immodest announcement in the Discourse: "I venture to say that I have never noticed anything in them [Descartes' senses] which I could not explain quite easily by the principles I had discovered" (Cottingham et al. 1985a, 144). There is no reason to think that Descartes is taking an uncharacteristically arrogant stance here. Rather, Descartes is merely laying out the consequence of his view that explanations are often easy to get, on his own conception of what explanations consist in.

However, although Cartesian explanations are in one sense quite easy to get, finding a Cartesian explanation is not a trivial project. It may require substantial theorizing. This is because, first of all, any Cartesian explanation of observed phenomena must be mechanical - otherwise it could not be grounded in first principles. For example, the explanations in terms of things' occult powers given by the Schoolmen will not do, because they appeal to various occult powers rather than the extension of material bodies. So, while finding an explanation is in one way quite easy, it is in another way quite hard, since the explanation must be mechanical. Moreover, the mechanical explanation in question must also be the clearest and most distinct explanation that is consistent with 
observed natural phenomena and all the laws of motion and first principles. Finding explanations of natural phenomena - such as gravitational pull, light refraction, and magnetism - that meet these conditions is not a trivial task.

I have argued that Descartes can allow himself to speculate about the underlying mechanical explanations of natural phenomena because the theories that figure in such explanations need not be regarded as true, and thus need not meet Descartes stringent epistemic standards for scientific theorizing more generally. But one might still wonder what the purpose is, for Descartes, of finding scientific explanations if the theories used in such explanations are not to be regarded as true. For if the theories that Descartes proposes to explain such phenomena do not meet the epistemic standards Descartes set for himself, it is hard to see why Descartes would have spent so much time giving such explanations in the Principles. What value, if any, is there in giving mechanical explanations for natural phenomena if these explanations are bound to give us only the uncertain knowledge that Descartes explicitly claims we should reject?20

The answer is that Cartesian explanations have epistemic value that is independent of the epistemic value of the mechanical theories that figure in such explanations. In short, the multitude and variety of such explanations are indicative of the explanatory power of the first principles. Consider, for example, the following passage (and others quoted immediately below):

${ }^{20}$ Recall here the passage from the Rules quoted in section 2, which concludes that we should "reject all [...] merely probable cognition and resolve to believe only what is perfectly known and incapable of being doubted" (Cottingham et al. 1985a, 10). 
And since all natural phenomena can be explained in this way, as will become clear in what follows, I do not think that any other principles are either admissible or desirable in physics (Cottingham et al. 1985a, 247).

Of course, Descartes was well aware that he could not actually carry out all explanations of all natural phenomena in the Principles, but he nevertheless considered himself to have done enough to suggest that the project could, in principle, be completed:

Admittedly, I have not dealt with all things, for this would be impossible. But I think I have explained all the things I have had occasion to deal with in such a way that those who read the book attentively will be convinced that in order to arrive at the highest knowledge of which the human mind is capable there is no need to look for any principles other than those I have provided (Cottingham et al. 1985a, 184).

As Descartes explains here, the fact that natural phenomena could all be explained by these principles justify Descartes' claim that the principles of extension, thought and God's infinite perfection are the only first principles that govern natural phenomena. The greater number and variation of phenomena that can be deduced from these few principles, the greater is the case for Descartes' contention that genuine science need not proceed by applying any other principles.

Note that it is precisely this explanatory comprehensiveness of his first principles that Descartes needs to justify in his philosophical system. Descartes acknowledges that everyone grants that the first principles are true and self-evident:

$[\ldots]$ they have been known for all time and indeed accepted as true and indubitable by everyone, with the sole exception of the existence of God, which some people have called into doubt because they have attributed too much to sensory perceptions, and 
God cannot be seen or touched. Yet although all the truths which I include among my principles have been known for all time by everyone, there has, so far as I know, been no one up till now who has recognized them as the principles of philosophy, that is to say, as the principles which enable us to deduce the knowledge of all the other things to be found in the world (Cottingham et al. 1985a, 184).

As Descartes explains here, the question is not whether the first principles are true, but whether the first principles are all we need. Deduced phenomena can help justify Descartes' positive answer to that question, even though they cannot help to justify the principles themselves.

Summing up, the way to alleviate the apparent tension between Descartes' requirement of certainty and his speculative scientific explanations is to notice that Cartesian explanation can be certain even if the mechanical theories which figure in them are not. Not only can Descartes thus uphold his requirement of certainty despite the speculative nature of the theories he uses in his explanations, but because scientific explanations still have to satisfy the requirement of being deducible from first principles, these explanations still connect the first principles with the natural phenomena by a deduction. And the fact that such deductions from first principles are possible for all the observed natural phenomena that Descartes considers in turn supports Descartes' claim that these first principles are the only principles one needs in science.

\section{Other Advantages}

I have argued that the account of Cartesian explanations presented in section 5 helps us resolve the tension described in section 3. That's the main advantage of this 
interpretation, but there are other advantages as well. None of these additional advantages are meant to constitute conclusive arguments for the interpretation, at least not taken separately. My contention is that together with resolving the tension from section 3, they constitute a strong overall case for this reading of Descartes.

First of all, there is considerable textual evidence for this interpretation. We have seen a lot of that evidence already, scattered throughout this paper. Let me now draw attention to one particularly illuminating remark in the Principles, viz. the title of section 204: "With regard to the things which cannot be perceived by the senses, it is enough to explain their possible nature, even though their actual nature may be different" (Cottingham et al. 1985a, 289). ${ }^{21}$ On the current interpretation, Descartes is here expressing precisely the point that his mechanical explanations need not proceed through mechanical theories that one can be certain are true; rather, the nature of the underlying mechanisms "may be different". ${ }^{22}$ Of course, as Descartes explains in the article, the mechanical theories must at least "correspond accurately with all the phenomena of nature". But that's it. If Descartes has met this requirement, he says, "I have achieved enough" (Cottingham et al. 1985a, 289).

Admittedly, Descartes goes on to express his hope that his readers will recognize that he has achieved more than this, claiming that his explanations are also "at least

${ }^{21}$ The French addition adds: "and this is all Aristotle tried to do".

22 Note how closely this talk of explaining the possible natures of things rather than their actual natures matches the distinction between how-possibly and why-actually explanation. Indeed, it appears that Descartes was here expressing, to the best of his abilities, the thought that howpossibly explanations can be "good enough" when why-actually explanations are not available. 
morally certain" in the title of section 205. Indeeed, the title of section 206 adds that his explanations even "possess more than moral certainty", i.e. absolute certainty. But it is striking that Descartes does not see it as a requirement on the success of his overall project in the Principles that the theories appealed to in his proposed explanations must be true. Although Descartes clearly hopes that the theories he has proposed will perhaps be recognized as possessing some level of certainty (moral or absolute), his main contention is clearly that the natural phenomena he has considered could be explained in the mechanistic manner he proposes. Indeed, Descartes is quite clear about this in the body of the section, which ends with Descartes claiming that once we accept certain basic pieces of Descartes' mechanical worldview,

$[\ldots]$ it seems that all the other phenomena, ot at least the general features of the universe and the earth which I have described, can hardly be intelligibly explained except in the way I have suggested (Cottingham et al. 1985a, 291).

Note that the object of Descartes purported absolute certainty here is not the various scientific theories he puts forward in the preceeding sections, but the proposition that (the general features of) all natural phenomena can only be explained in the way Descartes has proposed, i.e. mechanically. So Descartes is not claiming to be certain about the mechanical theories to which he appeals in his scientific explanations, but about the general philosophical doctrine that natural phenomena can only be explained mechanically.

A second advantage of the current interpretation is that it makes better sense of the peculiar nature of the observed natural phenomena that Descartes considers in the Principles. While the phenomena that Descartes attempts to explain in the Principles are 
many and varied, the ones he focuses on - such as magnetism, light refraction, and gravity - all share the feature of not wearing their mechanical nature on their sleeves. Accordingly, the non-attentive mind might conclude, as William Gilbert (1958/1600) did regarding magnetism some fifty years before Descartes wrote the Principles, that there must be a non-mechanical reason why magnets behave as they do. Gilbert's theory, if true, would constitute a counterexample to Descartes' claim that his first principles suffice to explain all natural phenomena. In that case, Descartes would have to admit that there is at least one more principle - presumably, some kind of principle of magnetism governing natural phenomena.

On the current interpretation, the main purpose of discussing all these phenomena is, simply enough, to show Descartes' scholastic opponents that mechanical explanations can be given even for these seemingly non-mechanical phenomena. It may require an ingenious mind like Descartes', but it is certainly not impossible in principle, as Descartes shows the reader repeatedly by example. Furthermore, given the enormous number of phenomena that Descartes can explain in this manner we would seem to be warranted in generalizing from these examples, as Descartes reminds us late in part IV of the Principles:

Consider how amazing are the properties of magnets and of fire, and how different they are from the properties we commonly observe in other bodies [...] In this book I have deduced the causes - which I believe to be quite evident - of these and many other phenomena from principles which are known to all and admitted by all, namely the shape, size, position and motion of particles of matter. And anyone who considers all this will readily be convinced that there are no powers in stones and plants that are so mysterious, and no marvels attributed to sympathetic and antipathetic influences 
that are so astonishing that they cannot be explained in this way. In short, there is nothing in the whole of nature (nothing, that is, which should be referred to purely corporeal causes, i.e. those devoid of thought and mind) which is incapable of being deductively explained on the basis of these selfsame principles; and hence it is quite unnecessary to add any further principles to the list (Cottingham et al. 1985a, 278-9).

The argument is clearly that since so many phenomena can be explained by appealing only to Descartes' three first principles, we should "be readily convinced that" all phenomena can be explained in a similar manner, i.e. mechanically. If so, then not only is it wrong that there are counterexamples to Descartes' claim that these are all the principles we need. But, further, Descartes' claim is actually supported by the fact that such a great variety of phenomena can be explained mechanically. The failure of Descartes' opponents to find even a single thing he can't explain with his first principles constitutes a strong case for thinking that these are all the principles one needs to explain all natural phenomena whatsoever.

Third, and finally, the current interpretation fits quite nicely with Descartes' dialectical position when writing the Principles. As is well known, Descartes was writing in a time of widespread scholasticism, where explanations of natural phenomena were typically given in terms of things' occult powers. Descartes rejected these scholastic explanations, of course. But the difference between Descartes and the Schoolmen goes deeper than rejecting or accepting the particular explanations given in the Schools. Descartes rejected the general approach of giving scholastic explanations for natural phenomena in terms of occult powers. So, Descartes' dialectical position was not simply one of opposing the explanations given in the Schools, but one of opposing the very idea that one should ever appeal to explanations of a particular sort. 
Now consider what it is to be in a dialectical position where you and your opponents disagree on the very nature of an adequate explanation. One way to go about convincing people in your audience is to show them some of the many explanations that can be given for various natural phenomena on your conception of explanations. Notice that although it is certainly a good thing if the explanations one gives in such a dialectical situation seem certain and self-evident, that's not necessary as far as this project goes. All that is required is to convince one's audience that some explanation or other of the right kind can be given for the phenomena in question. If one succeeds in doing that, one has made progress in convincing the audience that one's conception of explanation is the correct one, even if one does not also succeed in convincing the audience that the particular explanations one gives are those explanations of this kind that one should end up endorsing.

The interpretation of Descartes I have been arguing for accounts for this quite nicely. Descartes' way of arguing for his new approach to natural philosophy in the Principles is to show his audience what kind of explanations are available for various kinds of natural phenomena. The theories that figure in these explanations need not be certain, because being certain is not essential to figuring in a good scientific explanation. Nevertheless, such explanations can serve their dialectical role quite well, because their existence illustrates that there are good explanations of the form that Descartes is arguing for. Consequently, they show that Descartes' general approach to scientific explanations can do the work required of it, viz. be used to explain all the various phenomena one encounters in nature. 


\section{Conclusion}

I have given an interpretation of Descartes' writings about scientific theories and explanations that enables us to take Descartes' views on scientific explanations in the Principles as adequately expressed and consistent with his earlier writings. On this interpretation, the theories appealed to in Cartesian explanations need not be regarded as true, and thus such theories do not fall within the scope of Descartes' requirement of certainty. Much more could be said, however, about Descartes' requirement of certainty as it relates to his scientific theorizing more generally. Most importantly, it is clear from the text that Descartes seems to have thought that at least some of his scientific theories are morally, if not also absolutely, certain. It is a further question - one that I have not really tried to answer here - to what extent, in what sense, and why, Descartes did believe that these theories were certain. My claim here has been the slightly more modest one that this certainty is not required for the overall success of Descartes' scientific and philosophical project in the Principles of Philosophy.

\section{Acknowledgements}

I am very grateful to Alan Nelson for encouragement and very helpful feedback on an earlier version of this paper. I would also like to thank the editor and two anonymous reviewers for $H O P O S$ for thoughtful comments which, among other things, led me to clarify central aspects of the interpretation offered in section 5. 


\section{References}

Clarke, Desmond M. 1982. Descartes' Philosophy of Science. Manchester: Manchester University Press.

Clarke, Desmond M. 1992. "Descartes' Philosophy of Science and the Scientific Revolution." In The Cambridge Companion to Descartes, ed. John Cottingham, 258285.Cambridge: Cambridge University Press.

Cottingham, John, Stoothoff, Robert, and Murdoch, Dugald, eds. 1985a. The Philosophical Writings of Descartes, Vol. I. Cambridge: Cambridge University Press.

Cottingham, John, Stoothoff, Robert, and Murdoch, Dugald, eds. 1985b. The Philosophical Writings of Descartes, Vol. II. Cambridge: Cambridge University Press.

Dray, William. 1957. Laws and Explanation in History. Oxford: Oxford University Press.

Florka, Roger. 2001. Descartes's Metaphysical Reasoning. New York and London: Routledge.

Gaukroger, Stephen. 1989. Cartesian Logic. Oxford: Oxford University Press.

Garber, Daniel. 1978. "Science and Certainty in Descartes." In Descartes: Critical and Interpretative Essays, ed. Michael Hooker, 114-151. Baltimore, MD: John Hopkins University Press.

Garber, Daniel (1993). "Descartes and Experiment in the Discourse and Essays." In Essays on the Philosophy and Science of René Descartes, ed. Stephan Voss, 288-310. Oxford: Oxford University Press.

Garber, Daniel. 2001. Descartes Embodied: Reading Cartesian Philosophy Through Cartesian Science. Cambridge: Cambridge University Press. 
Gilbert, William (1958/1600). De Magnete. Translated by P. F. Motteley. New York, NY: Dover Books.

Hattab, Helen. 2009. Descartes on Forms and Mechanisms. Cambridge: Cambridge University Press.

Hacking, Ian. 2006. The Emergence of Probability: A Philosophical Study of Early Ideas about Probability, Induction and Statistical Inference. $2^{\text {nd }}$ edition. Cambridge: Cambridge University Press.

Hempel, Carl G., and Oppenheim, Paul. 1948. "Studies in the Logic of Explanation." Philosophy of Science 15:135-175.

Nelson, Alan. 2015. "Logic and Knowledge." In A Companion to Seventeenth Century Philosophy, ed. Dan Kaufman. New York, NY: Routledge.

Rogers, Brian, and Nelson, Alan. 2015. "Descartes and the Paradox of Deduction." In The Gods and Giants of Early Modern Philosophy, ed. Patricia Easton and Kurt Smith, 106-136. Leiden: Brill.

Normore, Calvin. 1993. "The Necessity in Deduction: Cartesian Inference and its Medieval Background." Synthese 96:437-454.

Owen, David. 1999. Hume's Reason. Oxford: Oxford University Press.

Salmon, Wesley C. 1992. "Scientific Explanation." In Introduction to the Philosophy of Science, ed. Merrilee H. Salmon et al., 7-41. Indianapolis, IN: Hackett.

van Fraassen, Bas G. 1980. The Scientific Image. Oxford: Clarendon Press.

Wong, David. 1982. "Cartesian Deductions." Philosophy Research Archives 8:1-19. 